\title{
O conceito de "ratio naturalis" entre os jurisconsultos romanos e Santo Tomás de Aquino
}

\section{Miguel Reale}

Os jurisconsultos romanos, como é reconhecido pela quasi unanimidade dos mais ilustres intérpretes do Direito Romano, não foram filósofos, nem nos deixaram teorias sistematizadas sôbre os problemas fundamentais da ordem jurídica do ponto de vista de sua justificação filosófica.

Juristas antes de mais nada, tiveram sempre as vistas voltadas para as questões postas pela prática e, nesse mister, se revelaram de uma precisão inexcedivel, aplicando um método que com razão foi considerado quasi que geométrico.

Esta apreciação inicial que fazemos revela, só por si, que não podiam êles ter chegado à noção de "ratio naturalis" da mesma forma e com a mesma penetração que podemos seguir e analisar na obra de Santo Tomás de Aquino, quem, na Idade Média, mais a fundo tratou dos problemas éticos e jurídicos.

Como observa Carle, o espírito utilitário e prático dos jurisconsultos romanos fez com que êles dessem uma feição toda especial, um significado todo particular àqueles mesmos conceitos e àquelas mesmas noções que, entre os gregos, constituiam objeto de pura especulação doutrinária. 
Foi o que aconteceu, como ainda observa Giuseppe Carle, com o conceito de ratio.

Entre os helenos as idéias de "razão" e de "justo" indicavam mais, ou para melhor dizer, representavam antes princípios que iluminavam o intelecto do que principios ou preceitos que ligassem a vontade, destinados a reger imperativamente a conduta humana.

O citado jurista italiano observa tambem que foi, exatamente, por significar mais um preceito imperativo ligando a vontade do que uma pura categoria destinada a explicar as relações humanas, que a noção de ratio dos estoicos encontrou preferivel acolhida entre os jurisconsultos romanos, que a interpretaram como ordo e proportio.

Embora se possa achar algo exagerada a distinção de Carle, o certo é que os juristas de Roma tiveram de ratio naturalis uma noção eminentemente pragmática, não podendo ser exatamente compreendida se a abstrairmos ou isolarmos do processo histórico que levou à sua aceitação pelos juristas.

Em verdade, pensamos que não é possivel formar uma exata noção de ratio naturalis em Roma sem verificarmos, por assim dizer, a sua razão de ser.

Os romanos, como dissemos, eram possuidores de um admirável senso de medida na prática do Direito e vieram formando o seu magestoso edifício rebus ipsis dictantibus ac necessitate exigente.

$\mathrm{Na}$ construção desse sistema normativo, ao qual se atribuiu o valor de uma geometria dos preceitos de conduta, os jurisconsultos se serviram de seu senso jurídico consubstanciado na ratio juris.

A ratio juris, a pesquiza realista da necessidade da norma compativel com os fatos múltiplos da vida, bastavalhes para dar a justificação e o sentido da tarefa ingente que iam realizando, criando, paulatinamente, as soluções indispensáveis à garantia e à tutela dos interesses da sociedade romana dos primeiros tempos. 
Mas Roma cresceu, alargou pela península o poder do seu império, estendeu para fora as malhas do seu poderio. Entrou, então, em contacto com outros povos e outros direitos, e o romano - até então encerrado no pequeno mundo que tinha como fronteiras a vontade e o espírito da Urbs - o romano sentiu necessidade de tomar posição em face dessas novas ordens sociais e desses valores jurídicos diversos. Assim, ao lado do jus civile, que a ratio juris por si só explicara satisfatoriamente, surgiu um novo direito, o jus gentium, não um direito estrangeiro, como poderia parecer, mas um verdadeiro direito romano, como diz von MAYER, formado histórica e comparativamente em contacto com o direito que regia outras nações.

Pois bem, foi então que os jurisconsultos romanos sentiram que o seu majestoso edifício jurídico estava sem uma justificação mais profunda. A noção de "consenso comum" - que, aliado à de ratio juris, bastara para explicar e justificar o Direito Romano propriamente dito, o jus civile não era bastante para dar o motivo de um fato que os juristas não podiam deixar de observar: a igualdade de muitos preceitos de Direito em Roma e entre povos que nenhuma ligąąão haviam tido com os Romanos.

Como explicar êsse fato? Como explicar que gentes distantes tivessem os mesmos preceitos fundamentais, que pareciam privilégio dos romanos e, não raro, motivo de seu orgulho?

Foi, então, que o conceito de ratio naturalis entrou no sistema do Direito Romano, vindo, por assim dizer, a constituir a cúpula do lento e progressivo trabalho multi-secular.

Se há um direito igual entre todos os povos, se há um conjunto de normas comum a todos; é que êsses preceitos resultam necessária e universalmente da razão natural que é sempre a mesma por toda parte.

Chegados, pois, à compreensão da ratio naturalis, não apenas por simples motivo especulativo, mas por uma profunda exigência da própria obra jurídica realizada, os jurisconsultos romanos já encontraram em Roma uma ad- 
miravel preparação filosófica, que podia não ser original, mas que não deixava de apresentar elementos de grande alcance para o jurista.

A doutrina dos estóicos era, por assim dizer, a doutrina que dominava incontestavelmente entre os homens mais representativos do pensamento romano. Não vamos aqui relembrar a influência exercida por ZENo e seus continuadores sôbre os juristas de Roma, através de Panecio, de PosıDônio e, especialmente, de CícERo.

Entretanto, as palavras que Cícero escreveu sôbre a ratio naturalis, sôbre ela fundando toda a ordem ético-jurídica, não podiam deixar de exercer a mais profunda e decisiva influência sôbre os cultores da jurisprudência.

Segundo o autor do De Legibus, a ratio naturalis é universalmente idêntica, não é uma em Roma e outra em Atenas, nem uma ôntem e outra hoje. E' conatural a todos os povos e a todos indistintamente indica o que deve ser feito e o que deve ser evitado. Ela é universal, e o Direito que dela resulta não pode ser revogado, por maior que seja a autoridade que a pretenda negar. E Cícero, não obstante todo o seu orgulho de civis romanus compenetrado da grandeza dos poderes do Estado Romano, declara que nem mesmo o Senado e o povo teriam autoridade bastante para suspender a força dos preceitos da ratio naturalis.

Pois bem, foi à luz da ratio naturalis que os jurisconsultos romanos deram fundamento ao jus gentium, a cuja noção haviam chegado, como definitivamente o demonstraram Puchta e Savigny, historicamente, ou, para melhor dizer, atravez de um processo empírico.

Ao lado do jus civile pôs-se, então, o jus gentium, e GaIo - cuja explicação histórica parece ser a que mais estava em harmonia com o pensamento romano - GAIO fundamenta o "direito das gentes" de uma forma lapidar: "Omnes populi, qui legibus et moribus reguntur, partim suo proprio, partim communi omnium hominum jure utuntur. Nam quod quisque populus ipse sibi jus constituit, id ipsius 
proprium civitatis est: vocaturque jus civile, quasi jus proprium ipsius civitatis. Quod vero naturalis ratio inter omnes: homines constituit, id apud omnes peraeque custoditur vocaturque jus gentium, quasi quo jure omnes gentes utuntur".

Nesse texto, Gaio, ao mesmo tempo que limpidamente estabelece a divisão dicotômica do direito em civile e gentium, explica que êste é a própria expressão da ratio naturalis, é o Direito que a razão natural constitue entre todos os. homens.

Não é um Direito fundado no consenso, nem é mera resultante do imperativo governamental; está acima da autoridade e do consenso, é inerente à própria natureza humana. Fundando o jus gentium na ratio naturalis, GaIo não vê necessidade de procurar outro direito: o jus gentium é expressão da ratio naturalis, ou seja, de todos aqueles preceitos que resultam necessariamente da própria natureza racional do homem.

E' só mais tarde que - ainda por influência dos estóicos - surge a idéia de distinguir um jus naturale de conteudo próprio e diverso do jus gentium e que seria, no dizer de UlPIANo, aquele que a natureza ensina aos homens e aos animais, tal como a união do macho e da fêmea, a procriação. dos filhos e a sua criação. UlPIANo considera que, quer no mar, quer na terra, todos os animais, mesmo os selvagens, são considerados istius juris peritia.

Entretanto, pensamos, com apoio nas considerações feitas por Savigny em um dos suplementos ao $1 .^{\circ}$ volume do seu "Sistema do Direito Romano atual", que essa noção de um jus naturale distinto do jus gentium tem para Ulpiano um mero valor especulativo e que êle, depois, nos momentos de aplicação do princípio, contenta-se com a divisão dicotômica, ou seja, com a discriminação entre jus gentium et civile, que é a mais própria da jurisprudência romana.

Vimos, assim, como a idéia de ratio naturalis, após longo e natural processo evolutivo do Direito Romano, veiu a ser incorporada neste como sua cúpula e complemento. 
A noção de ratio naturalis em Roma não desempenha, porém, apenas o papel de fundamento justificativo de toda a ordem jurídica, mas representa tambem um princípio de alto alcance prático nos domínios da aplicação do Direito.

Inteligências penetrantes, fortemente orientadas no sentido dos problemas da vida com os seus imprevistos e as suas particularidades, os jurisconsultos romanos não podiam admitir a idéia de que fosse pleno e sem lacunas o sistema das normas positivas,

Seguir sempre e a todo propósito o que a ratio juris faz resultar do jus strictum, das normas ditadas pelo legislador, seria incidir em vendadeira negação do direito: summum jus, summa injuria.

Por outro lado, nem sempre a lei tem a necessária clareza. E' ambígua, comporta interpretações dispares. Então, necessário e justo é que se interprete de acôrdo com a ratio naturalis, segundo as exigência da natural distinção do justo e do injusto. O conceito de ratio naturalis é aqui o de aequitas, que vem dar o sentido humano dos preceitos positivos.

Como se vê, a noção do ratiiio naturalis entre os romanos tem, como observa Solari, um sentido profundamente humano. Em geral, não representa, uma noção transcendente, mas formada no próprio sistema de experiência histórica. Daí, acrescenta Solari - que é hoje um dos mais penetrantes historiadores da Filosofia do Direito na Itália - daí a concepção de “jus naturale" que lhes é própria, com um significado "social" que se não deve esquecer.

Que relação há entre êsse conceito de ratio naturalis e, por conseguinte, de jus naturale e a doutrina de SANTo Tomás de Aquino?

Viktor Cathrern, em sua "Filosofia Moral" e, mais extensamente, em sua obra especial sôbre o Direito ("Direito, Direito Natural e Direito Positivo") declara que entre os jurisconsultos romanos e Santo Tomás há uma inegável "harmonia de vistas". 
Não podemos concordar inteiramente com o ilustre mestre da nẹo-escolástica. Grandes são, sem dúvida, as semelhanças entre a doutrina da ratio naturalis dos juristas romanos e a de Santo Tomás, mas como é possível separar êsses conjuntos de princípios da época em que se formaram, do modo pelo qual se formaram, do sentido que lhes deram os juristas da Roma pagã e o incomparável mestre medieval?

Em primeiro lugar, lembramos o que já dissemos e foi bem acentuado pelos historiadores CARLYLE. Os jurisconsultos romanos não desenvolveram uma indagação aprofundada sôbre a ratio naturalis. Advogados, ou melhor, legistas e jurisperitos, não tinham cultura filosófica bastante que lhes desvendasse toda a força da noção, que haviam tomado como fundamento e justificativa da ordem jurídica. Empíricos e pragmáticos, aceitaram - como dizem os já citados CARLYLE - as idéias filosóficas correntes entre os homens cultos de Roma. A influência dos estóicos, mais do que do directo conhecimento e da amadurecida reflexão das obras de Zeno ou de Crisipo, resultou talvez mediatamente das opiniões, que, entre a elite romana, constituiam, por assim dizer, a filosofia corrente.

Já o mesmo não se dirá de Santo Tomás, que do Direito não cuida como jurista, como técnico, mas como filósofo e teólogo. Ao tratar dos problemas éticos, ao chegar no capítulo relativo à justiça, o doutor angélico volta as suas vistas penetrantes para a ordem das relações humanas, e enquadra a sua doutrina do Direito no sistema geral de sua filosofia, de seu sistema.

Daí a primeira diferença que vemos entre a sua indagação profunda e a dos jurisconsultos romanos. Para êstes, a noção de ratio naturalis é, por assim dizer, um princípio primeiro. Panteistas como eram, como panteistas eram os estóicos, os juristas de Roma identificaram a ratio naturalis com a própria razão universal que, segundo a doutrina de Zeno, governa o mundo. À luz do estoicismo, na- 
tureza e razão se identificam, e viver segundo a natureza é viver de conformidade com a razão.

Se, como em geral estão de acôrdo os autorizados intérpretes do pensamento de Paulo, Gaio, Celso, Ulpiano etc., se êles eram estóicos em filosofia, a noção de ratio naturalis era noção primeira, porque era a própria razão divina imanente na ordem do Universo.

Na doutrina de Santo Tomás de Aquino, vemos que o monismo não existe, que a noção de ratio naturalis é noção que se prende à uma noção primeira, à de Deus, o qual se não confunde com o universo, que não é a alma do mundo, mas é o criador do mundo e o seu legislador. Segundo Santo Tomás, em verdade, a lex naturalis, que é expressão da capacidade inata e conatural que tẹmos de discernir o bem do mal, o justo do injusto, se subordina à lex aeterna, que é a própria razão, a própria ordém imutável e inerente a Deus.

A nossa razão natural é, no dizer de Santo Tomás, uma centelha da razão divina. Nós, ao nascer, já trazemos o senso do bem e do mal, do justo e do injusto. Discernimos o que deve e o que não deve ser feito. E é a razão natural, sempre igual em todos os homens e em todos os lugares, que é "ordem e medida"; é a razão natural que nos dá os preceitos de Direito válidos para todos os sistemas de Direito e que se reduzem a êste fundamental: "o bem deve ser feito e o mal deve ser evitado".

Isto posto, passa SANTo Tomás a estudar, em relação aos preceitos da ratio naturalis, o significado e o valor do jus gentium e do jus civile.

Os preceitos da ratio naturalis são eternos e universais, não podem ser derrogados pelo legislador ou pelo costume, como já dissera Cícero - em palavras de repassado entusiasmo - ao se referir à recta ratio, sempiterna, congruens, e como já ensinara Aristóteles entre os helenos distinguindo o justo por natureza do justo por lei.

Mas êsses preceitos, não obstante essas propriedades que os colocam acima de toda ordenação positiva, não bas- 
tam por si sós para o governo dos homens, e é necessário que deles tiremos as conolusões necessárias e, indo alẻm, cheguemos a determinações mais remotas, segundo as exigências sempre mutáveis e renovadas da vida.

Ora, as conclusões necessárias, que resultam do jus naturale e que são - por conseguinte - comuns a todos os povos, constituem o jus gentium. Ésse Direito, nem por ser objeto de legislação positiva, deixa de ser de Direito Natural. Os preceitos do jus gentium, segundo SANto Tomás, sendo expressão da ratio naturalis, são, como dissera GAIo, aqueles que se constituem entre todos os povos e são consagrados pela legislação dos diversos Estados, mas, nem por isso, nem pelo fato de se lhe ter dado positividate, deixam de ser preceitos de jus naturale.

Em suma, a ratio naturalis nos dá o jus naturale: o jus naturale é o conjunto de todos aqueles preceitos que são inerentes à própria natureza racional do homem. Uma parte desses preceitos realiza-se como jus gentium, como conclusão necessária dos preceitos de direito natural. Êste, por conseguinte, abrange aquele, como a conclusão se contém na premissa.

Por fim, Santo Tomás explica a natureza do Direito estrito, do direito civil, do direito que é peculiar a cada povo e que é variavel em função das peculiaridades dos diferentes povos. O jus civile não resulta do jus naturale como conclusão дecessária, mas sim como determinação, como especificação em face dos casos concretos que não podem ser regidos pelos preceitos gerais do jus gentium.

Essa ordem de normas, que constitue o jus civile, é formada por determinações do legislador no sentido do bem comum e segundo as exigências da razão em casos particulares. Daí a definição precisa de lei que nos deixou SANTo Tomás, a qual - no plano do jus civile - seria uma determinação feita pelo legislador dos preceitos do jus naturale em função da particularidade dos casos ocorrentes.

Como nota Legaz Lacambra, a concepção jurídica de SANTo Tomás é, de certa forma, uma concepção escalonada, 
ou para repetirmos a expressão empregada pelo ilustre mestre espanhol, é uma Stufenau a partir da idéia de lex aeterna até à de lex humana, a partir do jus naturale até ao jus civile.

Em torno do conceito de ratio naturalis, como expressão de ratio divina, eleva o doutor angélico a sua doutrina do Direito, ainda tão viva em nossos dias.

Que profunda seja nessa concepção a influência dos jurisconsultos romanos é o que se não poderia negar. Na Summa Teologica, ao tratar do problema das leis e da justiça, Santo Tomás a ćada passo se refere aos grandes vultos do Dirẹito Romano, cujos ensinamentos êle ora aceita integralmente, ora os reelabora, pondo-os em harmonia com a doutrina aristotélica e a concepção ético-cristã do universo e da vida.

A sua concepção de jus gentium, entretanto, como direito formado por conclusões necessárias do jus naturale, não nos parece que coincida com a dos jurisconsultos romanos. Em primeiro lugar, êstes chegaram, como vimos, ao jus gentium atravez de um processo histórico-comparativo, e a nação de ratio naturalis veiu se juntar ao sistema elaborado, vivificando-o com um significado profundo que os juristas não cuidaram de indagar em todas as suas consequências.

Santo Tomás seria, de certo modo, como que o filósofo que vem completar a obra dos empíricos, tirando das noções estabelecidas todas as suas resultantes fecundas.

Somos, pois, de opinião que há semelhança entre o conceito de ratio naturalis de Santo Tomás e o dos juristas de Roma, neste sentido que, tanto para o filósofo medieval, como para os jurisconsultos, ela é um princípio natural de ordem, conatural a todos os homens, igual por toda parte, da qual resultam os preceitos do Direito que não podem ser revogados pelos legisladores e pelos costumes, que declara o que deve ser feito e o que deve ser evitado, que fundamenta a ordem jurídica positiva, que preenche as lacunas 
do jus trtictum, dando nascimento às normas de equidade, que, ainda quando violadas continuam a brilhar com o seu eterno brilho.

Entretanto, entre uma concepção e outra há uma diferença radical. O conceito de ratio naturalis entre os romanos é naturalista, é terreno, é categoria $a s e$, que se basta a si mesma e que não se sub-ordena a nenhuma outra. E' uma noção subsistente.

Já a noção de ratio naturalis na doutrina tomista, não. se pode compreender fora de sua concepção geral do universo e da vida. A ratio naturalis é uma participação do homem à razão divina nos limites impostos à criatưra.

Em um caso, é um conceito de jùristas e há críticos como Voigt, Bergbohn e Solari, que lhe não atribuem um valor positivo; seria como que um luxo dos jurisconsultos pragmáticos, ou um mero direito "in fieri", um direito ideal.

Embora não concordemos com esta opinião, embora não nos pareça possivel negar o alto e real significado da ratio naturalis em Roma, não podemos deixar de notar aqui a diferença que a mesma ideia assume na obra dos juristas romanos e na doutrina de SANTo Tomás.

Entre um e o outro há um processo histórico milenar, há a experiência do Cristianismo, subordinando a ordem humana à ordem eterna, a compreensão dos imperativos da ratio naturalis à luz da ratio divina.

São Paulo, 2 de Selembro de 1940. 